\title{
Information Systems and Intra-Organisational Power: Exploring Power \& Political Aspects Associated With the Adoption of a Knowledge Sharing System in an IT Services Department
}

\author{
Lahiru Attygalle, Liisa von Hellens, and Leigh Ellen Potter \\ School of Information Communication Technology \\ Griffith University, Brisbane, Australia
}

\author{
s.attygalle@griffith.edu.au, I.vonhellens@griffith.edu.au, \\ l.potter@griffith.edu.au
}

\begin{abstract}
It is widely accepted that the successful adoption of information systems in organisations is dependent on the contextual factors relating to organisational culture, power, structure, and strategy. Of these, organisational power has been least investigated, especially in relation to information systems of a knowledge sharing context. Moreover, IS and power theories belonging to the emergent perspective of power have not been explored in detail in recent times. In this paper, an attempt is made to illustrate the intra-organisational power and political aspects associated with designing, implementing, using, and maintaining an information system used for sharing knowledge. This was achieved by investigating a case study focused on a knowledge sharing system of an IT services department in an Australian university. The findings were derived based on the analysis conducted using the elements of Political Variant of the Interaction Theory (PVIT), which we argue is a theoretical framework belonging to the emergent perspective of power. The analysis provided insights into how the investigated information system shaped, and was shaped by, the power relations of the organisational context. Moreover, the investigation confirmed the analytical strength and the applicability of the PVIT to modern case studies despite its age and lack of use. Based on the findings implications for future use of the PVIT are also drawn in this paper.
\end{abstract}

Keywords: Information system adoption, Political variant of the interaction theory, Emergent perspective, Information systems and intra-organisational power, Knowledge sharing system, IT service department.

\section{Introduction}

Material published as part of this publication, either on-line or in print, is copyrighted by the Informing Science Institute. Permission to make digital or paper copy of part or all of these works for personal or classroom use is granted without fee provided that the copies are not made or distributed for profit or commercial advantage AND that copies 1) bear this notice in full and 2) give the full citation on the first page. It is permissible to abstract these works so long as credit is given. To copy in all other cases or to republish or to post on a server or to redistribute to lists requires specific permission and payment of a fee. Contact Publisher@InformingScience.org to request redistribution permission.
The importance of investigating social and contextual factors relating to information systems adoption in organisations is illustrated by a number of scholars in the literature (Kling, 1977; Markus, 1983; Orlikowski, 1992; Thomas, 1994; Walsham, 1993). It has been posited that these factors consist of organisational culture, power, structure, and strategy (Kling, 1980; Lin \& Silva, 
2005; Walsham, 1993). However, over the years organisational power has had the least attention in comparison to organisational culture, structure, and strategy, when investigating information systems related phenomena (Silva, 2007). One such phenomenon is information systems used for sharing knowledge.

Knowledge sharing is one of the spheres of a broader research agenda called Knowledge Management - a field, which has been studied widely in the recent past (Alavi \& Leidner, 2001; Schultze \& Leidner, 2002). The resource based view of the organisation coupled with the transition from information workers to knowledge workers in firms has attracted many researchers to this field (Freke, 2005). Despite the growing number of studies in the area of knowledge sharing and related information systems, organisations still experience various difficulties in deploying effective knowledge sharing strategies among their organisational units (McDermott, 2000; Walsham, 2001). These difficulties more often than not are social problems relating to organisational culture, organisational power, and organisational structure and strategy, which in general require further attention from researchers (Walsham, 2001). Although organisational culture, structure, and strategy relating to knowledge sharing has been studied moderately in the literature (De Long \& Fahey, 2000), intra-organisational power and politics in relation to knowledge sharing and information systems in general has not been explored in depth (Walsham \& Hayes, 2001).

This paper investigates a knowledge sharing context of an IT service department in an Australian University, to bring to light intra-organisational power and political aspects associated with implementing, using, and maintaining an information system used for sharing knowledge. The paper adopts the emergent perspective of power (Jasperson et al., 2002) and employs Markus' (1983) Political Variant of the Interaction Theory (PVIT), which we argue (in PVIT Model section) belongs to the emergent perspective of power, to achieve its purpose. PVIT is regarded as a classic in information systems research (Lee, Myers, Pare, \& Urquhart, 2000), but has not had much attention in the literature (excluding Lapointe \& Rivard, 2005, 2007). The investigation described in the paper adopts an interpretive paradigm of research (Hirschheim \& Klein, 1989; Klein \& Myers, 1999; Walsham, 2006), which is carried out by means of a qualitative case study (Benbasat, Goldstein, \& Mead, 1987) of the said IT service department and is based on the development of an Honours dissertation (Attygalle, 2009).

The findings of this paper shed light to relationships between organisational power relations and an information system, as a result of using the PVIT as a theoretical lens to look into the case study. It illustrates the adoption process of an information system (used for sharing knowledge) from its design, development, and maintenance are shaped by intra-organisational power relations, and that these power relations are also shaped by the system in place. In addition, it was found that, despite its age and the lack of use in empirical studies, the PVIT still possesses a great degree of analytical strength and is well suited to analyse a qualitative case study (of present) involving intra-organisational power and information systems.

The structure of this paper is as follows. First, a review of the literature relating to intraorganisational power and information systems is made, bringing to light the 'emergent perspective of power'. Second, the theoretical framework used in this study (PVIT) is introduced along with its background, assumptions, and congruency to the emergent perspective of power. Next, the case study is described followed by the methodology adopted for this study. The paper then provides a detailed analysis and discussion of the case using the PVIT. Lastly, the paper concludes by reflecting on the findings brought to light by the application of PVIT to the case study and by providing implications for future research. 


\section{Literature Review}

Research into intra-organisational power and politics relating to information systems did not emerge until the beginning of the 1980s. Despite the lack of studies, the importance of investigating information systems phenomena in organisations - from a power and political lens was especially emphasised by several scholars (Bloomfield \& Coombs, 1992; Jasperson et al., 2002; Walsham, 1993). A recent review of power related studies in information systems recorded 82 studies dating back to 1980 (Jasperson et al., 2002). Some of these studies have emphasised the importance of the power phenomena in order to better comprehend information systems, where as a minority has viewed 'power' as a dark inhibitor/force that has negative impact on information systems. Furthermore, in their review, Jasperson et al. (2002) used three lenses based on the work of Markus and Robey (1988) to look into IT and power related studies that have emerged since 1980: the technological perspective which view that information technology changes the power structures of an organisation; the organisational perspective which recognise that social actors in an organisation use power to change the way information technology is managed and used; and finally the emergent perspective which combines both the technological and organisational views to posit that information systems and technology both impact and are impacted by the distribution of power in an organisation. Markus and Robey (1988) formulated these perspectives based on the conceptions of casual agency relating to information technology and organisational change.

Based on the review of Jasperson et al., (2002) it is evident that a majority of research has been conducted in the technological and organisational perspectives. In fact Jasperson et al. (2002) have made calls for more contributions to the emergent perspective. This notion has been echoed by Markus \& Robey (1988) in relation to organisational change where they claim that emergent perspective "requires detailed understanding of the dynamic organisational processes in addition to knowledge about the intentions of actors and the features of information technology" (p. 589), and thus they argue that it necessitates a higher level of complexity in comparison to the other two perspectives, resulting in the difficulty of constructing and deploying models.

Although the emergent perspective is comprehended in a number of ways in the literature (as a view of applying structuration models of technology (Orlikowski \& Robey, 1991, as a view of using IT as a catalyst to trigger reciprocal causes and effects that shape the outcomes of the technology and the organisational setting (Orlikowski, 1992), and as a view postulating "the uses and consequences of IT emerge unpredictably from complex social interactions (Markus \& Robey, 1988 , p. 588)), from the perspective of this paper, we adopt a basic understanding of it primarily based on the work of Jasperson et al. (2002). We argue that emergent perspective of power views the adoption process of an information system impacts and is impacted by the power relations of the organisational setting. In other words, "power concerns may affect how individuals and organisations adopt technology, design systems, train users and promote (hinder) projects - whether these activities are explicitly political or not" (Jasperson et al., 2002, p. 410).

Even though limited in number, the studies in the emergent perspective shed light on interesting insights. Markus (1983) in her study of exploring the implementation of a management information system observed that the information system allowed information (that assist in dealing with uncertainty) to be distributed in non random ways where certain employees have more access to information than others. She believed this gave rise to employee 'resistance' to the system in place. Although resistance is generally regarded as a negative thing, Markus (1983) affirmed the determination of 'resistance' being good or bad is dependent on the vested interest of a group or a person. Lyytinen \& Hirschheim (1987) argue a similar notion but in relation to information systems failure. They claim that failure of a system is more or less the embodiment of a perceived situation rather than actual failure of the system, and such embodiments can be the result of a political process. 
Bloomfield \& Coombs (1992) investigated the debate of whether information technology centralises or decentralises power structures in an organisation and concluded that neither is true and that information technologies in place are themselves outcomes of power struggles. Robey \& Markus (1984) postulated that system development can be both a rational and a political process; thus it is important for participants to be aware of the rituals that take place in the development process. Another study belonging to the emergent perspective of power is Robey \& Boudreau's (1999) research of user resistance, where they affirm that equal attention should be given to propositions and oppositions, as actions taken by one party are bound to be opposed by another due to power differences. Brown (1998) in his study argued that narratives in organisational settings are an important technique used by groups and individuals to understand and give meaning to information technologies of the setting.

It should also be mentioned that a great majority of studies that view intra-organisational power from the emergent perspective (and studies in other perspectives in general) have focused on design and implementation phases of an information system (excluding the studies by Lin \& Silva, 2005; Markus, 1983; Orlikowski, 1992) but not on post implementation settings. Moreover, the theoretical frameworks discussed in the emergent perspective of power have not been employed in a knowledge sharing context of an IT service department/organisation. Although no specific calls have been made by scholars to investigate these deficiencies, the authors of this paper believe that they present limitations in the literature, which need to be addressed. For that reason, one such theory - as illustrated in Jasperson et al., (2002) (Markus' (1983) Political Variant of the Interaction Theory) - is chosen as the theoretical framework that guides the data analysis of the study described in this paper. This framework is introduced in the next section.

\section{Political Variant of the Interaction Theory}

The theoretical beginnings of the PVIT go back to the work of Kling (1980). In his insightful paper Social Analysis of Computing: Theoretical Perspectives in Recent Empirical Research, Kling (1980) identified six distinct theoretical perspectives that can be used to analyse the social impact of computers in organisations. Interactionism was one of the six perspectives and was concerned in viewing social phenomena "as constructed from the interaction of people and groups as they create and respond to socially defined meanings" (Kling, 1980, p. 67). Moreover, interactionists perceive the field of computing as a domain where many individuals (designers, managers, users, consultants) with divergent, overlapping, and conflicting interests are brought together (Kling, 1977, 1978; Scacchi, 1981); but each individual defines the situation he or she works in based on the interactions (Kling, 1980). Hence, actions of each individual are seen as self interested and situated in a complex web of ongoing activity. Kling (1980) explains this using an example of how the deployment of a new automated material control system can offer rich satisfying opportunities to some individuals while at the same time providing novel concerns for others.

Markus (1983) building on the work of Kling (1980) used these fundamental insights of the interaction theory to derive a framework that explains group resistance of computer systems in organisations. The theory, termed Political Variant of the Interaction Theory (PVIT), builds on the premise that system resistance is caused by an interaction between organisational participants and the system concerned. Markus (1983) employs intra-organisational power and politics as a variant to explicate these interactions and provide meaningful explanation to the resisting behaviour of groups and individuals towards a financial information system of an organisation.

\section{PVIT Model}

The Political Variant of Interaction Theory (PVIT) consists of six elements that can be used to identify and categorise events and activities surrounding an information system and intraorganisational power relations, which have occurred over a period of time. Moreover, the inter- 
connections between these elements depicted in the theory provide rich insights into relationships of information systems and power relations in an organisation (Markus, 1983). According to Markus (1983) information systems in organisations distribute data/information in non-random ways, which results in some employees gaining more power and control over others. From this stems the fundamental notion of PVIT - that "information systems frequently embody a distribution of intra-organisational power among key actors affected by its design" (Markus, 1983, p. 442). The PVIT model is depicted in Figure 1 and explained below.

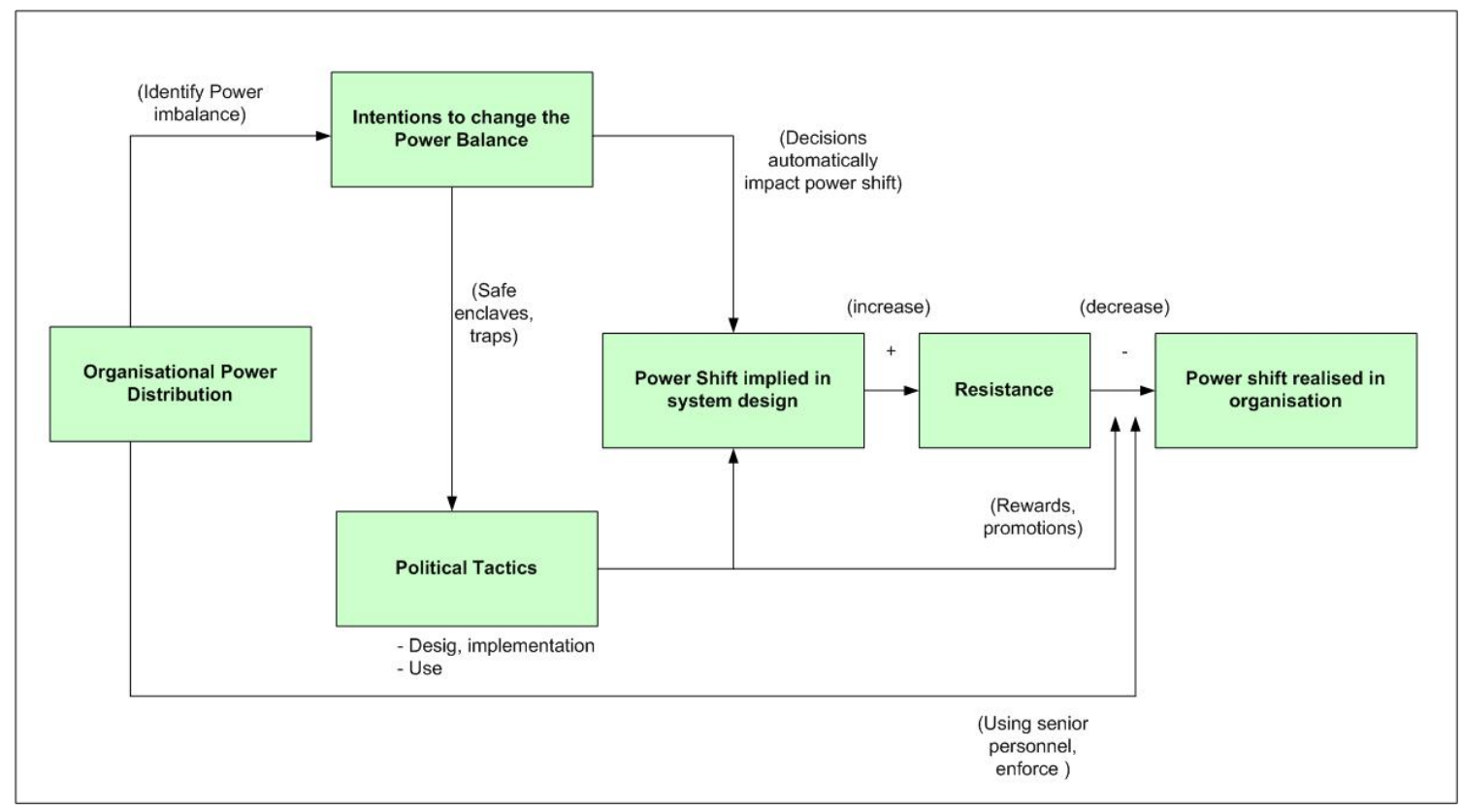

Figure 1: Political Variant of the Interaction Theory

Every organisation at any given time has a power structure attached to it. A power structure can be defined as a still image of the power balance in an organisation at a given particular time (Thomas, 1994). These power structures consist of power relations that are influential in driving the work practices of an organisation (Lapointe \& Rivard, 2007). Most of these power relations are fluid in nature, unstable, and evolve overtime and get reshaped (Markus, 1983; Orlikowski, 2000; Thomas, 1994). Such evolvements are caused by actions of organisational employees whose motives are driven by a desire to disrupt and perhaps change the existing power balance of the organisation, quite possibly because they see/foresee a loss of power and authority with the existing developments in the organisational setting, or they perceive an opportunity to benefit from others' loss of power by enforcing change. Hence, these actions taken to materialise a disruption become political in nature and are termed by Markus (1983) as 'political tactics'- which from an information systems' perspective can be acts such as introducing a new information system or modifying an existing one (control of access to data and distribution of data). This is complimented by Thomas (1994) who claims that "choices of technology could be influenced as much by efforts to alter structure and power relations as they could by efforts to reinforce or reproduce existing relations" (p. 229).

When such acts are performed, and power relations within the organisation begin to reshape, signs of resistance appear to surface from factions that have been disadvantaged by the disruption (Lapointe \& Rivard, 2005). Markus (1983) defines this resistance as acts performed by the disadvantaged parties to make up for the loss experienced in the power imbalance. However, of all disadvantaged people, only some will most likely to resist with strength due to misperception of the loss and to avoid criticism and changes (Lapointe \& Rivard, 2007). Markus (1983) further states 
that the strength of resistance is related to the size of loss and its perceived importance and is dependent on the vertical and horizontal structures of the organisations. To be more precise, if the cause for resistance is up the organisational hierarchy (vertical), there is more chance for less resistance; where as if it is across the organisational level (horizontal) such as among peers and colleagues, there is more chance for high resistance (Markus, 1983).

Resistance could take several general forms, from disengaging in work practices, ignoring the new system in place, raising concerns to the hierarchy and forming alliances against the disruptive tactics (Winfield, 1991). Lapointe and Rivard (2005) add further emphasis to this by positing a spectrum of resistance behaviours, from being passively uncooperative to engaging in physically destructive behaviour (Marakas \& Hornik (1996) as cited in Lapointe \& Rivard, 2005), or from lack of cooperation to sabotage (Carnall (1986) as cited in Lapointe \& Rivard, 2005). It should also be mentioned that PVIT treats resistance neither good nor bad (Markus, 1983). It maintains that the labelling of resistance as good or bad is dependent on the vested interest of the groups involved in context; which links back to the fundamentals of the interaction theory described before.

When encountered with resistance, attempts are then made by the advantaged parties of the power imbalance - in the form of further political tactics and influence - to bring the resistance under control (Markus, 1983). This is done in order to reduce the impact of resistance on the transition process. An example of such a tactic is the introduction of rewards scheme for engaging with the new/modified system in place (Robey, 1979) or direct influence from a highly respectedauthoritative person of the organisation (Markus \& Bjorn-Anderson, 1987). Overtime these attempts become a success or a failure which determines the reshaped power balance of the organisation (Markus, 1983).

From the emergent perspective adopted in this paper, the interconnections (Figure 1) between the elements of PVIT (as explained above) exemplify the impact of intra-organisational power relations on an information system as well as the impact of the concerned information system on the power relations. To elaborate more, the first three elements bring to light the nature of the power relations in the organisational setting and how they have prompted certain political tactics, such as the design and implementation of an information system; thus proving the impact of the power relations on an information system. The consequential events and reactions (from the sense of intra-organisational power) of having (using) such an information systems in place is illustrated by the last three elements of the PVIT. These include the power shifts incurred by the system, the resistance and interventions to reduce resistance, and resulting power balance in the organisation. In other words these elements demonstrate the impact of the concerned information system on intra-organisational power relations of the organisation. From this explication we establish that PVIT fits in to the emergent perspective of power defined in this paper.

\section{PVIT Assumptions}

There are number of explicit assumptions that underlie the PVIT - some which were implicitly mentioned above. However, it is necessary to clearly distinguish these assumptions as they become inherent in providing the ground work for the theory and its application to a particular organisational context.

The PVIT is primarily driven by the assumption described by Markus (1983), which is that "[information] systems have no inevitable impacts on the organisations which employ them; ultimately, impacts will depend upon the choices made by people about how to use them" (p. 443). In addition, resistance to computer system implementation and use is one of the key constructs discussed in the PVIT. The theory assumes that resistance is generated as a result of unequal distributions of intra-organisational power (among participants) caused by the interactions that take 
place between a computer system and its participants (Markus, 1983). Moreover, resistance is seen as a product of the setting (which includes users, designers \& consultants).

Building on that same notion, the theory further assumes that the purpose of information systems design, implementation, and use may well be intended to change/disrupt the existing power relations of an organisation (Markus, 1983). An organisational context is perceived by the PVIT as a setting consisting of individuals and groups with divergent interests and therefore conflict is inherent.

In regards to application, Markus (1983) affirms the analytical power of the PVIT can be used to its full potential, if it is applied to a case study. She justifies this claim by stating the identification of relationships between the different elements described in the theory, is best attained through a case study of an organisational setting. Her assertion is seconded by Lapointe \& Rivard (2005, 2007 ) in their studies of resistance and political tactics relating to information systems (using $P V I T)$ in three hospitals. This further justifies the theory's applicability for the study described in this paper.

\section{Organisation and System Studied}

The IT Services department is responsible for all information communication technologies and services of the University. The department consist of a three level hierarchical structure where organisational units, subunits and teams are allocated.

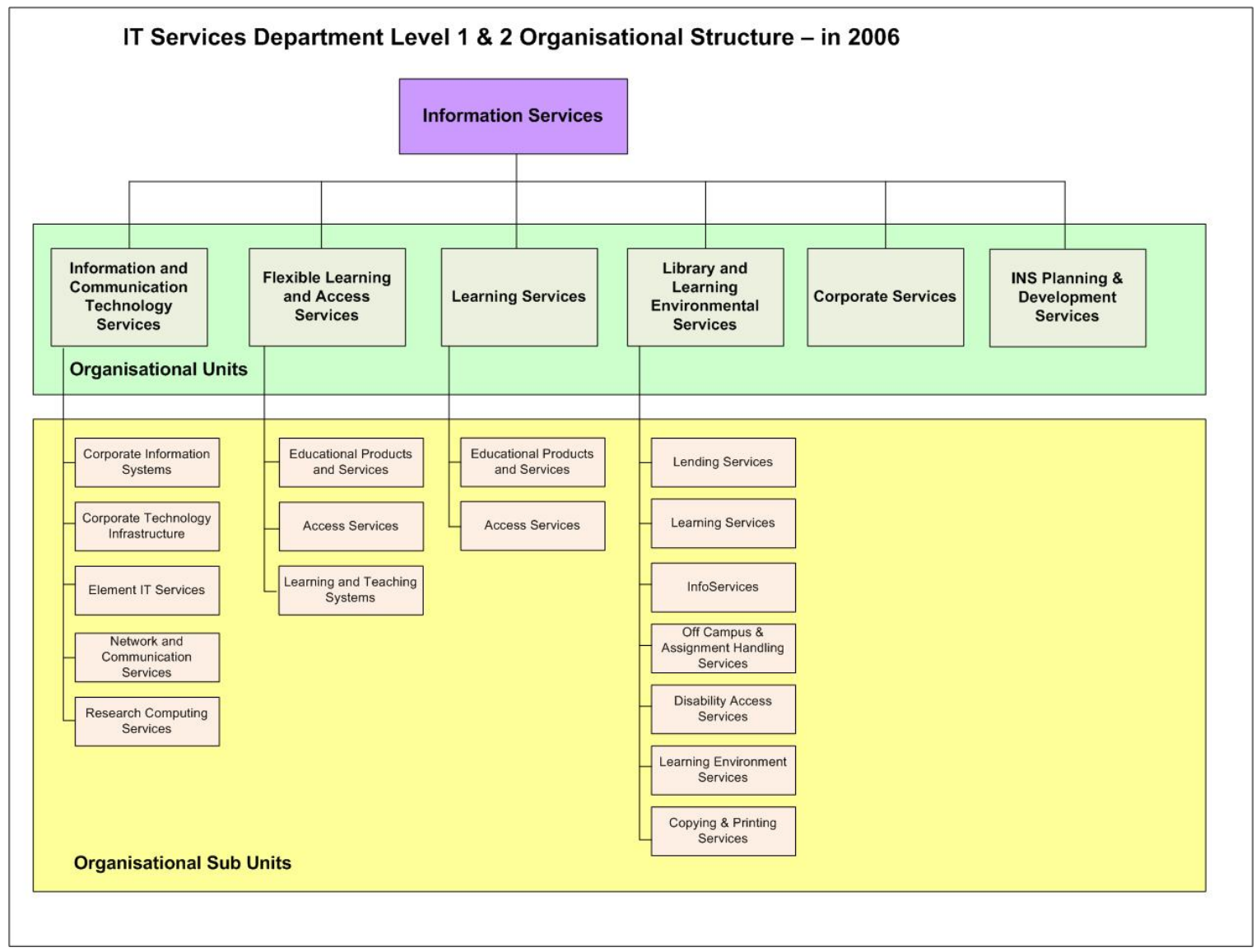

Figure 2: IT Services department level 1 and level 2 organisational structure

Under each organisational unit there are several subunits and under each subunit there are teams working on different areas related to the unit (Figures 2 and Figure 3). Inputs for the study de- 
scribed in this paper were gathered from an associate director of the Enterprise Information Systems subunit which falls under the Information and Communication Technology Services organisational unit (Figure 3), members of two teams in the EIS subunit - Messaging Services team and Web Services team, as well as members of the Corporate Services organisational unit (Figure 2).

A wide array of technical and non technical projects is undertaken by teams, subunits, and organisational units of the department on a regular basis. Most projects require collaboration between different organisational elements, and some even include collaboration and partnerships with external institutions. The department uses a standard project methodology derived from PRINCE2 ${ }^{\circledR}$ project management method for all its internal projects. Until November 2008, a subunit called Project Development and Services was responsible for overseeing the methodology, tracking, and budget spending of all projects within the department. However, after the advent of a new Pro Vice Chancellor (PVC) for the department in December 2008, the Project Development and Services subunit has been reshuffled in terms of its responsibilities - where the execution aspects of projects (tracking, monitoring, and controlling) are now spread across other organisational units that are close to the conduct of projects. In addition, the department is also in the process of setting up a Central Project Portfolio Office which will handle the standard project methodology and planning aspects which are relevant to all projects throughout the department. The current restructuring process is an attempt to increase the efficiency and productivity of the process used to conduct projects -which is in line with the department's strategic goals set under the guidance of the new PVC in December 2008.

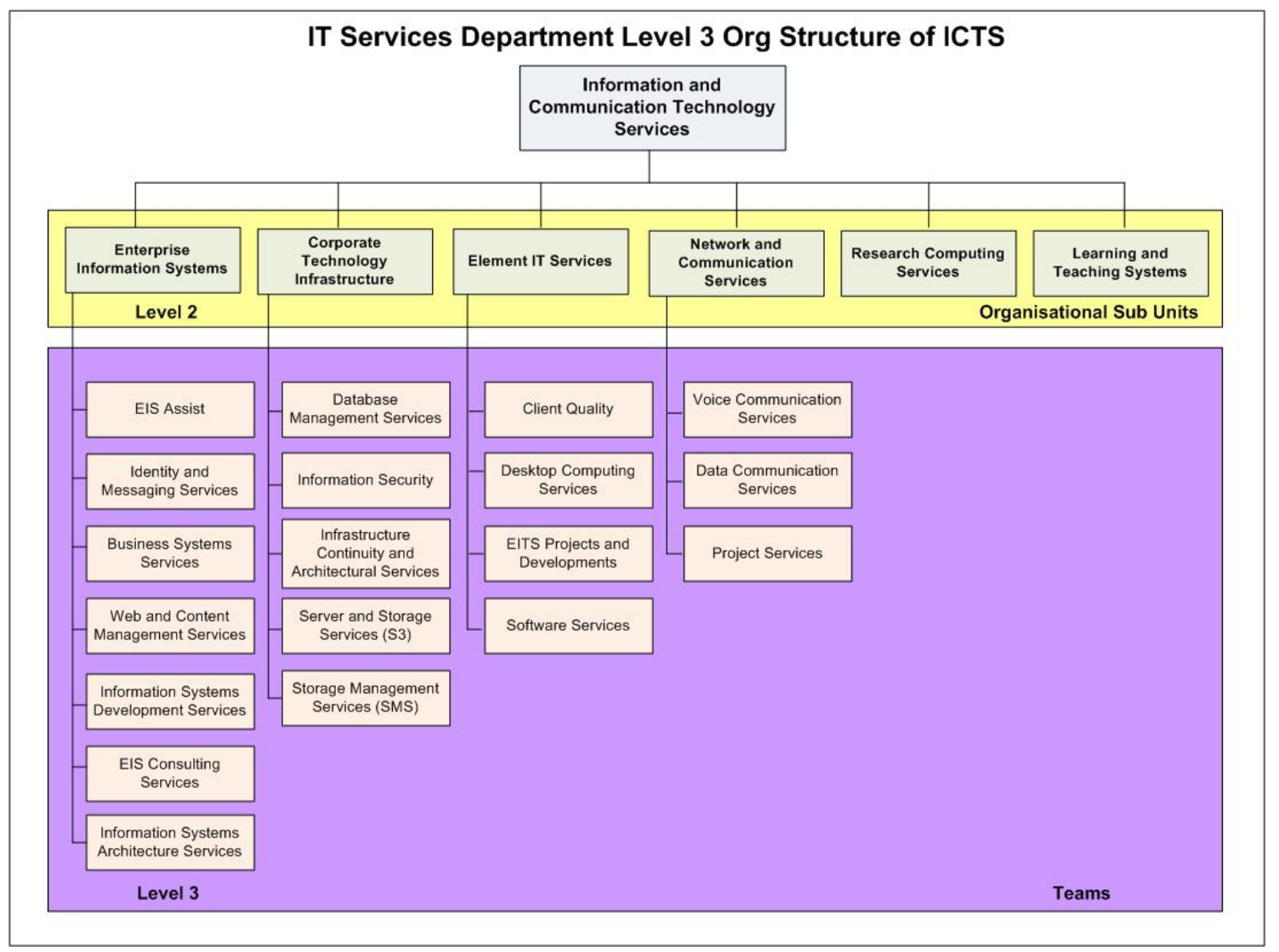

Figure 3: IT Services department level 3 organisational structure. 


\section{Power Structure}

The IT Services department consists of a hierarchical organisational structure. Except for minor addition and renaming of units, the central vertical and horizontal distributions of this structure have not undergone a significant change since 2006. (The 2006 organisational structure is provided in Appendices A and B). At the top of the hierarchy is the deputy vice chancellor for IT Services department who provides strategic direction and leadership to the department in order support and achieve higher level goals and objectives of the university.

The operational levels consist of organisational units, subunits, and teams which are headed by individuals in the respective organisational level. Hence, it is fair to assume that a centralised power distribution that follows the hierarchical structure is evident in the department. However, information technology departments of organisations are renowned for their technocratic cultures largely due to the technology specific work practices that take place in the departments (Handy, 1993). These work practices involve cross unit collaboration which is evident at IT Services department with the existence of various subunits and teams responsible for handling and collaborating on diverse technical (and non technical) tasks. Moreover, technocratic cultures are equipped with units of expert power (which can be defined as power to persuade based on expertise (Handy, 1993)) that can influence the work procedures. As described by Handy (1993) these cases of expert power unveil the more matrix type of structure and power distribution of an organisational setting, which to an extent has been concealed by the formal organisational structure depicted in company plans, figures, and policies.

\section{NOESIS System}

NOESIS is a system module that is used to document and share the lessons learned from projects that have been conducted by the IT Services department. It resides on a much larger system called the Project Management System which documents detailed information of projects from their inceptions to closures. The Project Management System is used by all personnel involved in projects as it is the main reference point for tracking the progress of a project against its estimated milestones, goals, and objectives. Despite NOESIS being a part of the Project Management System, the use of NOESIS is not mandatory. NOESIS was developed as a part of the initial implementation of Project Management System in 2006 launched by the Web Services team, and has not undergone any revisions or modifications up to date ( $1^{\text {st }}$ August 2009).

The primary purpose of the this system is to capture lessons from projects and make them available to other employees in the department - so that employees will be informed of lessons that have been learnt in each project by different people. As described by one of the subjects:

"...It [NOESIS] is where you would expect to capture the lessons that were unexpected during the project-something that the project was meant to be doing as a part of its scope, a standard project outcome and something you've learnt along the way."

The rationale behind that is to promote project related knowledge sharing within the department, which in turn will increase the capacity and the efficiency of the departmental knowledge base. The system basically consist of a simple, easy to use form-like interface where individuals can make contributions relating to their specific projects, which are linked to the respective project space on the Project Management System. Although, a set down procedure of recording lessons in NOESIS was not mentioned anywhere in the department, an implicit method is adopted by senior project managers and long tem project management staff who, according to NOESIS statistics, are the main contributors of the system. They initially focus on documenting all lessons in the formal (mandatory) documentation of the project. Once the formal documentation is complete, the documented lessons are analysed to identify particular lessons that are of global use to the department, which in turn are included in the NOESIS system. 
Despite its worthy purpose, over the last three years NOESIS has failed to attract many users in the IT Services department - which was perceived as a concern by the senior management and was brought to the researcher's (of this paper) attention. As of June, 2009 NOESIS consisted of lessons from 24 projects, which is less than five percent of the total number of projects conducted at the department since the introduction of NOESIS. It also appears this system is hardly promoted among teams, units, and subunits despite its lack of usage and department wide availability. Even when it is brought up in managerial meetings, it has not got much attention as exemplified by the following quote by a manager of the department.

"Last year we did a number of workshops with Project Managers...Probably 10 workshops with individual areas within [IT Services Department] around the project methodology as a whole, which the lessons learned database [NOESIS] and capturing lessons from projects as a part of the project may have been discussed"

\section{Methodology}

In 2009, the first author of this paper conducted a case study as a part of his Honours dissertation (Attygalle, 2009) which employed Markus' (1983) PVIT as a complete theoretical framework to identify relationships between intra-organisational power relations and an information system. The case study (explained below) consisted of investigating an IT service department in an Australian University. The information system examined was a knowledge sharing tool called NOESIS (a pseudonym), which was used to share lessons learnt of projects that were conducted in the department. Six semi-structured face to face interviews were carried out to gather primary data relating to the system, the work practices around it, and the power relations within the setting, over a period of one month (The data collection instrument is provided in Appendix C). The subjects interviewed consisted of members from the senior management, project managers, change managers, and a technical manager. These subjects were picked on the basis of their relevance to NOESIS and on the advice of the senior management of IT services department.

The data collection was supported by reviewing documentation relating to the context under investigation as they proved vital in gaining historical and background information. An interpretive approach (Klein \& Myers, 1999; Walsham, 2006) was used to analyse the data which included the use of Markus' (1983) PVIT as a 'sensitising device' (Klein \& Myers, 1999) to make sense of the contextual events illustrated in the data. The findings brought to light by the analysis were divided according to the six elements of the PVIT which are provided in the Findings and Discussion section of the paper.

\section{Findings and Discussion}

The discussion in this section is organised according to the elements of the PVIT model.

\section{Organisational Distributions of Power}

The first element of the PVIT, 'Organisational distribution of Power', was able to bring to light the power relations of the IT Services department before the NOESIS implementation. These were evident from the data relating to the organisational structure, political rule and the workforce dynamics of IT Services department in 2006 (Appendices A and B). The identified power relations included the existence of a bureaucratic politic rule where functional areas were centrally driven by a hierarchy of senior managers. But despite this bureaucracy, there was evidence to suggest that Messaging Services Team, popularly known as the 'Notes Team' possessed a degree of expert power, mainly because they administered critical projects relating to the Lotus Notes software package - which was the most widely used collaborative software suite in the university 
(Dialog, (2001) as cited in Gittoes, 2002), and was instrumental for most day-to-day tasks (e.g., email, calendar, instant messaging) as pointed out by one of the subjects.

"Lotus Notes is embedded in our day to day tasks. Whether it is email or appointments or collaboration, you end up with a Notes application someway or the other."

Marshall \& Brady (2001) claimed the administrators of such instrumental technologies in organisation, are perceived by others as 'experts' who are able to shape other's perceptions of the technology. Thus, the expert status had an influence on other teams of IT Services department as they perceived the Notes Team as a knowledge hub in regards to a majority of project lessons and tips. The following comments reflect on this,

"We have a few people [in the Notes Team] that know the vision where that particular technology wants to take, and everyone wants to go to them to funnel through them to sit their [everyone's] project's within that framework"

"I send the documentation that we [Notes Team] put on the blog...to the managers of the different support teams and then they put that in their locations... and soon WE become their 'call for help', NOT their senior managers"

Furthermore, none of the subjects during their interviews referred to the 'Notes Team' by its original name which is Messaging Services Team - which further illustrates the expert status the team has obtained in regards to the Lotus Notes software package.

\section{Intentions to Change the Power Balance}

In looking at the data using the second element of the PVIT ('Intentions to change the power balance'), certain actors' motivations to disrupt the existing power relations of IT Services department could be identified by inference. Interestingly, these motivations have a direct linkage to the notions discussed in the first element of the PVIT. The Notes Team handled key projects and possessed vital knowledge and, to a certain extent, was in a different league compared to other teams (as illustrated in the first element). Therefore, it can be argued that the senior management would have wanted the Notes Team to share its knowledge and lessons among others, so that others can learn and come up to a similar league - which would benefit the department as a whole. Moreover, by doing so one could expect the expert power of the Notes Team to reduce and remain at a less threatening level. A quote by one of the senior managers implicitly reflects on these premises.

"Even few years back we've always thought a central repository [for sharing knowledge] is ideal... where people can access online during their own time rather than having to run up to a specific individual or team on a constant basis to sort out queries"

From an interpretivist standpoint, these insights can be perceived as viable reasons for the senior management to come up with the decision to implement a centralised knowledge sharing system, supposedly aimed at sharing important lessons and experiences that come out of projects. The NOESIS was implemented after (mid 2006) these concerns and motivations were realised which further strengthens the above assertion. This provides a foundation for the discussion of political tactics used by the senior management in designing and implementing NOESIS, which are described in the next element of PVIT.

\section{Political Tactics (Design, Implementation, and Use)}

According to Lin \& Silva (2005) the adoption of an information system is more of a social and political process which involves various tactics. Moreover, Thomas (1994) suggests the attractiveness of a system is based not entirely on its functional attributes but also of its political and 
symbolic values. When the decision to implement NOESIS was made, the senior management made a number of tactics that appear to be of political nature. Many teams within the department (e.g., WS Team, EC Team, and Notes Team) had their own mechanisms of sharing knowledge, including team specific procedures and tools which were functioning well.

"The web team ...they share all their stuff through a website that they've created which is working for them, but we are using an IBM lotus notes applications"

Due to this the senior management may well have been uncertain of the impact NOESIS would have on these procedures. Moreover, they may have been concerned about the disruptive tactics that Notes Team could employ due to their expert power status. These notions help to clarify why a central guideline for using NOESIS was not set down when it was implemented. In fact, the absence of such a guideline illustrated the fact that individuals had to come up with their own procedure of using NOESIS, rather than having to follow a set of guidelines.

Furthermore, as mentioned in the case study the use of NOESIS was open to everyone and not made mandatory. However, it was mounted on a system which by and large had modules that were mandatory to use by project staff. In other words staff will have an opportunity to use $N O E$ SIS when ever they access the Project Management System to perform project related tasks. This is seen as an attempt to get more people involved in NOESIS without making it compulsory for use. Apart from that, there were signs of managerial influence as illustrated by the following quote which were directed at some teams to engage in NOESIS, which could also be seen as a 'political tactic' employed by the senior management.

"I have used it [NOESIS] during the projects... mainly because our manager was like you know... we really need to use it ..."

Bloomfield \& Combs (1992) concisely summarise the above notions by stating "the idea that designing an information system is equivalent to designing a power system, that such a system will realise power for the designers or, more commonly, their clients, may justifiably be viewed as a fantasy" (p.464).

\section{Power Shifts Implied by/in the System}

Using the fourth element of the PVIT ('Power Shifts implied by / in the system') as a lens to interpret the case study data was helpful in identifying the impact NOESIS has had on the power relations of IT Services department. After NOESIS was launched as a knowledge sharing tool, it attracted the attention of senior project managers who had been in the department for more than 10 years. These even included personnel from the senior management team, and they soon became the main contributors to NOESIS as explained by the following quote:

"My senior project manager would have put a lot of stuff in there [NOESIS], so that was more of a something he did than I did"

Furthermore, in the absence of a set guideline of 'how and what project lessons' to share on $N O$ $E S I S$, an implicit guideline emerged among these main contributors - which soon was followed by other contributors (refer to the case study). This acceptance of the implicit guideline raised the main contributors' (senior project managers') power and influence in the tool (NOESIS), which made them more like the 'go to guys' in relation to NOESIS (although they did not own it). As explained by Zuboff (1988) one should not necessarily need to have the formal authority of ownership over a system to influence others; such ownership can also be acquired through the control of interpretation and communication that occur in the particular system. 
However, this development made short-term and contract-based staff perceive that NOESIS was meant for senior project managers and long-term (permanent) staff of the department. The following quote reflects on this,

"The people that have been here for long time obviously know about it [NOESIS] and they use it"

Moreover, these staffs were constantly in doubt as to the types of contribution that need to be made to NOESIS, mainly because the lessons recorded in there could be viewed by anyone and everyone in the department.

“...Or whether someone's going to hold something against you if you've written something that you know... once it is in writing...you got to be sort of cautious you know..."

With these developments, there were anxieties of consequences in contributing to NOESIS in the minds of these short-term / contract-based staff as expressed by the above quote, which explains their lack of participation in the system.

\section{Resistance}

The 'Resistance' element was useful in identifying resistive behaviour towards NOESIS due to the events described in the previous elements of the PVIT. Apart from the fear of having to face undesired consequences as a result of contributing to NOESIS (briefly explained in the previous element), there were other resistive behaviour shown towards NOESIS.

For a start, distinct pessimistic claims (provided below) in regards to the purpose of NOESIS were raised by several employees, particularly by members of the Notes Team.

"[NOESIS] is not a critical tool. It may increase our knowledge about project management [if we use it] ...but it is not critical"

"[NOESIS] is for project management, and the lessons learned of projects. We have done many projects and we have learnt a many lesson but we have not used that [NOESIS] lessons learned tool"

Although these claims could be a result of the employees perceiving the system as not useful (Lapointe \& Rivard, 2007), in the case of the Notes Team, it is fair to suggest the claim has resistance attached to it. Such an assertion can be derived based on the findings discussed in relation to the Notes Team in the previous elements of the PVIT. For instance, one of the intentions for NOESIS to be put in place was to reduce the expert power of the Notes Team; hence, the team's resistance towards NOESIS occurs naturally.

Secondly, a lot of criticism was made of the NOESIS system from its functional characteristics to its usage. From a resistance point of view, interesting aspects of these criticisms were,

1. others already knowing the project lessons that one has learnt, so what is the point in sharing them in NOESIS?

"The lessons I've learned, the organisation may very well already know, so what is the point in putting them in there [NOESIS]",

2. contributions in NOESIS being open to anyone,

“...Or whether someone is going to hold something against you if you have written something that you know...once it is in writing...you got to be sort of cautious you know..." 
3. and, NOESIS lacked functional capacity to engage users in it,

"But how do you drill down to find that particular information? Or do you just read every comment in there [NOESIS]? And some of the lesson may not even make sense... and you might get a different interpretation of it"

In first two aspects resistance is focused on the consequences of using NOESIS. Especially in the first case, there is an impression that knowledge sharing using pre-existing informal ways is getting the word across to the others in the department, who require that particular knowledge; hence the use of NOESIS for the same purpose would be a waste of time and will leave room for redundancy.

According to Disterer (2001) the idea of revealing an employee's knowledge using a computer system can formulate anxieties in the minds of the employee. Hence, the department wide availability of NOESIS makes a participant anxious and uncertain of the contributions he or she is about to make. These anxieties stem from questions like "Who will read my post?" "Am I sure this is right?" "Is this lesson an obvious one?" "Have I explained it properly?" and act as a barrier for knowledge sharing (Disterer, 2001). As pointed out by Thomas (1994) the control over uncertainty (anxiety) resulting from a system is one of the key aspects that explain the distribution of power among groups of participants. In other words, when there is no control over such uncertainties, participants resist the use of the system and remain in safe enclaves (Hayes \& Walsham, 2000), which explains the second facet of resistance listed above.

The third aspect of criticism that outlined resistive behaviour is directly related to the functional characteristics of the NOESIS system. Basically, some participants (members of the External Collaboration Team) saw the system as less engaging and ineffective and therefore resisted its usage.

In addition, resistance was further made evident by the Notes Team's efforts in promoting the adequacy of their own systems (such as Lotus Team Room which they have a sense of control and ownership) over NOESIS to achieve the same purpose.

"The team room is there... it is always going to be there... if people wants to have access to it from another project, to go through what we have done... they are welcome to do so... it is not like restricted to our teams as such...but it is just way too much information for other teams to go through...they would not even know what they are looking for ... you know that is our repository for our projects..."

"There would be another way that you share knowledge, and you would not really use our team room which is more specific to our team"

Reflecting on these insights brought to light by the 'Resistance' element of the PVIT, there is a considerable amount of resistance directed towards NOESIS that has evolved since its commencement. However, it is noteworthy mentioning that none of the resistive behaviours were critical or radical in nature. For instance, no explicit and critical threats or demands were made from any workgroup about NOESIS in the case study. A plausible explanation to this could be the cause of resistance being vertical (up the hierarchy) where there is more chance for less resistance than horizontal (across the organisational level) (Markus, 1983).

\section{Political Tactics (To Counter Resistance)}

The case study data did not explicitly reveal tactics employed to counter the above described resistance. However, by looking at that data from a political lens, some of the tactics were identified as measures taken to reduce the resistance. It was clear that the Notes Team resisted the use of NOESIS and relied on their own processes (as mentioned in the previous sections) and they were largely responsible for handling critical projects similar to Lotus Notes upgrade project. De- 
spite the resistance, there is no evidence suggesting that the senior management has made any significant enforcement on the Notes Team to engage in NOESIS. Observing this from a political perspective, it can be reasoned that the expert status of the Notes Team remained despite the presence of NOESIS, and for that reason the management, like before, did not fancy disrupting the team's work practices through enforcement. Succinctly, it is a political tactic used by the senior mangers to cover up a previously imposed tactic (designing and implementing NOESIS) which did not bear fruit.

Even though there was resistance, NOESIS still had the nod of the senior project managers. Hence under their advice it was used more as an induction tool for new project managers that come on board rather than using it purely to share project lessons - a tactic that managed to reduce the criticism of NOESIS as illustrated below.

"Ideally they [new project managers] would come along and a part of the induction of the project manager we'd ask them to have a look at the lesson learned knowledge space, look for lessons generally in your area see whether it might relate to your project"

It is also interesting to point out that no modifications were made to the NOESIS system after its initial implementation. This could also be seen as a responding political tactic by the designers (including senior management) of NOESIS to the compliments, criticism, and resistance brought up by the NOESIS audience. For instance, the resistors did not necessarily request for functional modifications of the system (despite them voicing the functional flaws) as their resistance was largely political in nature; and non-resistors on the other hand were quite content with the system as it is. Hence, there was no reason for a system modification.

An interesting point worth mentioning here is that, despite the resistance, the senior management did not enforce the use of NOESIS nor did they decommission it; instead they ended up with a process that made both parties fairly content.

In addition the case study revealed an organisational restructuring process presently occurring at IT Services department. The reshuffling of Project Development and Services subunit and the development of the Central Project Portfolio Office illustrate the department's plans to become more decentralised and distribute project execution among functional areas, while centralising project leadership by informally gathering all project managerial staff under one unit. This is a distinct difference to the structure when NOESIS was initially implemented (Appendices A and B) and the flux could be for many reasons which are beyond the scope of this paper.

From a knowledge sharing and NOESIS system's point of view, the above reshuffle calls for a rethinking of NOESIS' purpose. This is because Information Systems (such as NOESIS) act as moderating variables that support the centralisation or decentralisation efforts of the organisation (Winfield, 1991). Moreover, the flux would compliment the existing work practices of teams which are already decentralised (eg: Notes Team, External Collaboration Team and Web Services Team). Therefore, it is not unreasonable to think that the restructuring is a sign of acceptance by the senior management of having a decentralised - matrix like structure to better handle projects in the department - after what was observed in using systems such as NOESIS. Thomas (1994) voices a reflection of this: "To change the way technology is used - or technological possibilities are conceived - would require a change in the distributions of status and power in the organisation it self" (p. 87).

\section{Power Shifts Realised in the Organisation}

In the final element of Markus' (1983) Political Variant of the Interaction Theory (PVIT) termed 'Power shifts realised in the organisation', a reflection is made on the present situation which has emerged as a result of the previous elements of the PVIT. As mentioned in the previous element, 
at present IT Services department is in the process of developing a Central Project Portfolio Office to compliment its vertical-decentralisation and horizontal-centralisation efforts. This was inferred as an attempt to compliment the decentralised work processes of teams such as the Notes Team. In fact, any centralisation and decentralisation attempts can be seen as instances of information politics (Bloomfield \& Coombs, 1992). In this light, it can be reasoned that teams such as the Notes Team still hold a degree of expert power even after three years since implementing NOESIS.

The expert power of Notes Team was further signified by senior management's decision to deploy knowledge sharing techniques adopted by the Notes Team. Notes Team 's resistance towards NO$E S I S$ was illustrated by voicing the adequacy of their own processes and systems. Not only were these processes observed and considered by the senior management, they even adopted them at departmental as well as managerial level. The increased use of Blogs as illustrated by the quotes below provides evidence to this.

"I think we find the blog pretty useful, because we can word it the way we want to in plain English, put Graphics in there... where as if we put it on the web some where it has to abide all conditions. And there are definite restrictions"

"Blogs are starting to be the trend here. The PVC for IT Services department...she now has her own Blog...which gets updated with what she is doing in different events and what the department have done"

Hence, 'the use of NOESIS and events surrounding it over the past three years has in a way increased the expert power and status of the Notes Team' is not an ambitious, but rather a realistic assertion that can be made based on this analysis.

From NOESIS system's point of view, the senior managers and long term project staff of the department are still the main contributors to the system. However, with the tactic to use NOESIS as an induction tool for new project managers, the system could play a part in shaping newcomers with the influence of its main contributors. Although such an outset will result in further interesting power shifts in the department, the manifestation of that is yet to be seen.

\section{Conclusions}

The previous section engaged in applying theoretical elements of the PVIT to the case study and derived interesting insights of the context under investigation. In this concluding section a reflection is made on those insights as a collective whole to comprehend the bigger picture of the context. The idea of comprehending the whole from "preconceptions about the meanings of its parts and their interrelationships" is a fundamental principle of interpretive research studies (Klein \& Myers, 1999, p. 71). Such a comprehension, as illustrated in this section, will then shed light on the overarching notions that address the purpose of this paper - to bring to light intraorganisational power and political aspects associated with implementing, using, and maintaining an information system used for sharing knowledge.

One of the key things that are coming out of the discussion conducted above is the linkage between sections. Although that is mainly due to the relationships described in the PVIT, it is interesting to note that the majority of the findings in the research context complimented these relationships. These relationships suggest the connectedness between information systems and intraorganisational power. In a nutshell, the senior management's intentions to change existing power relations by employing the NOESIS system and adopting political tactics to get more user attention to it, and teams such as the Notes Team showing signs of resistance towards NOESIS by political means and, therefore, making the senior management adjust their course of actions, proves this linkage between intra-organisational power relations and information systems. 
To elaborate more, first, the impact of rolling out Lotus Notes Software Package at IT Services department gave a sense of expert to the Notes Team. Thus, there is reason to suggest the concerned information system of this paper (NOESIS) was a result of intra-organisational power struggles at IT Services department. Secondly, the design and use of the system was shaped using various political tactics by the senior management. This is in line with the thoughts expressed by Thomas (1994):

Organisational leaders seek to shape or guide the worldviews of their participants in ways that will induce certain behaviours and discourage others. They do so by means of rules, rewards, socialisation activities, performance measures, job descriptions and the like... (p.29)

Thirdly, resistance towards NOESIS was made evident by teams (e.g., Notes Team), by making use of their expert power and enforcing political tactics such as voicing the 'suitability' of their existing systems over NOESIS, thus making a negative impression of NOESIS on the minds of other employees. Lastly, there is evidence to suggest the power relations of the Notes Team have influenced the senior management to have a rethink of the purpose of NOESIS and possibly to alter it as more of an induction tool for new project managers rather than using it as department wide knowledge sharing system. In addition there is also reason to believe the power relations may have prompted the restructuring of the IT Services department. This reflects on the overarching view of Benson (1977):

Organisational [subunit/team] participants are not in any single sense captives of the roles, official purposes, or established procedures of the organisation [subunit/team] ... they may become very purposeful in trying to reach beyond the limits of their present situation, to re-construct the organisation [subunit/team] in accord with alternative conceptions of its purpose, structures, technologies, and other features. (as cited in Thomas, 1994, p. 29)

In conclusion, this paper has brought to light interesting insights relating to intra-organisational power and politics associated with implementing, using, and maintaining an information system used for sharing knowledge in an IT service department of an Australian University. These insights reveal how an information system shapes and is shaped by the power relations of its organisational context. The paper derived these insights by analysing a qualitative case study of the said department through the lenses of Markus' (1983) Political Variant of the Interaction theory $(P V I T)$ - which is belonging to 'emergent perspective' of power (Jasperson et al, 2002) that has attracted little attention in the literature. Hence, the findings of this study have contributed to the limited literature where domains of information systems, knowledge sharing, and intraorganisational power (belonging to the 'emergent perspective', Jasperson et al., 2002) overlap. From the theoretical framework's point of view, the PVIT, despite its age (26 years) and its lack of usage in empirical studies lends itself as a complete theoretical framework capable of analysing organisational phenomena (relating to power, politics, and information systems). This paper has demonstrated its applicability and usefulness to a modern day case study of a knowledge sharing context in an Australian University. On a concluding note, the paper makes a call to conduct further empirical studies using the PVIT in order to identify possible extensions to its theoretical concepts (that were formulated 26 years ago) as well as to further develop the emergent perspective and establish its stance in the literature. 


\section{References}

Alavi, M., \& Leidner, D. (2001). Review: Knowledge management and knowledge management systems: Conceptual foundations and research issues. MIS Quarterly, 25(1), 107 - 136.

Attygalle, L. M. (2009). Perceptions of knowledge and power: Exploring the relationships between intraorganisational power and information systems used for sharing knowledge, at an information technology department of an Australian University. Honours Dissertation, Griffith University, Brisbane.

Benbasat, I., Goldstein, D. K., \& Mead, M. (1987). The case research strategy in studies of information systems. MIS Quarterly, 11(3), 369 - 386.

Benson, J. (1977). Organizations: A dialectical view. Administrative Science Quarterly, 21, 20 - 40.

Bloomfield, B. P., \& Coombs, R. (1992). Information technology, control, and power - The centralization and decentralization debate revisited. Journal of Management Studies, 29(4), 459 - 484.

Brown, A. D. (1998). Narrative, politics and legitimacy in IT implementation. Journal of Management Studies, 35(1), 35 - 58.

Carnall, C. A. (1986). Toward a theory for the evaluation of organizational change. Human Relations, $39(8), 745-766$.

DeLong, D., \& Fahey, L. (2000). Diagnosing cultural barriers to knowledge management. Academy of Management Executive, 14(4), 113 - 127.

Dialog. (2001). Griffith University invests $1 \mathrm{~m}$ in IT. Brisbane.

Disterer, G. (2001). Individual and social barriers to knowledge transfer. Paper presented at the 34th Hawaii International Conference on System Sciences, Hawaii.

Freke, V. (2005). Definitions, reuse and technology: How context impacts technology support for knowledge management. Unpublished $\mathrm{PhD}$ Thesis, Griffith University, Brisbane.

Gittoes, D. (2002). A groupware implementation: Impact upon organisational culture within an Australian University. Unpublished Honours Dissertation, Griffith University, Brisbane.

Handy, C. (1993). Understanding organizations (4th ed.). Victoria: Penguin Books Ltd.

Hayes, N., \& Walsham, G. (2000). Safe enclaves, political enclaves and knowledge working. In C. Prichard, R. Hull, M. Chumer, \& H. Willmott (Eds.), Managing knowledge: Critical investigations of work and learning (pp. 69-87). Basingstoke: Macmillan.

Hirschheim, R., \& Klein, H. (1989). Four paradigms of information systems development. Communications of the ACM, 32(10), 1199 - 1216.

Jasperson, J., Carte, T., Saunders, C., Butler, B., Croes, H., \& Zheng, W. (2002). Review: Power and information technology: A metatriangulation review. MIS Quarterly, 26(4), 397 - 459.

Klein, H., \& Myers, M. (1999). A set of principles for conducting and evaluating interpretive field studies in information systems. MIS Quarterly, 23(1), 67 - 94.

Kling, R. (1977). The social dynamics of technical innovation in the computing world. Symbolic Interaction, $1(1), 132$ - 146.

Kling, R. (1978). Patterns of segmentation and intersection in the computing world. Symbolic Interaction, l(2), $24-43$.

Kling, R. (1980). Social analysis of computing: Theoretical perspectives in recent empirical research. Computing Surveys, 12(1), 61 - 110.

Lapointe, L., \& Rivard, S. (2005). A multilevel model of resistance to information technology implementation. MIS Quarterly, 29(3), 461 - 491.

Lapointe, L., \& Rivard, S. (2007). A triple take on information system implementation. Organization Science, $18(1), 89-107$. 
Lee, A., Myers, M., Pare, G., \& Urquhart, C. (2000). Three perspectives: If Markus' 1983 classic study, "Power, politics, and MIS implementation, were being reviewed today". Paper presented at the International Conference on Information Systems, Brisbane, Australia.

Lin, A., \& Silva, L. (2005). The social and political construction of technological frames. European Journal of Information Systems, 14, 49 - 59.

Lyytinen, K., \& Hirschheim, R. (1987). Information systems failures: A survey and classification of the empirical literature. Oxford Survey in Information Technology, 4, 257 - 309.

Marakas, G. M., \& Hornik, S. (1996). Passive resistance misuse: Overt support and covert recalcitrance in IS Implementation. European Journal of Information Systems, 5(3), 208 - 220.

Markus, L. (1983). Power, politics and MIS implementations. Communications of the ACM, 26(6), 430 444.

Markus, L., \& Bjorn-Andersen, N. (1987). Power over users: Its exercise by system professionals. Communications of the ACM, 30(6), 498 - 504.

Markus, L., \& Robey, D. (1988). Information technology and organizational change: Causal structure in theory and research. Management Science, 34(5), 583-598.

Marshall, N., \& Brady, T. (2001). Knowledge management and the politics of knowledge: Illustrations from complex products and systems. European Journal of Information Systems, 10, 99 - 112.

McDermott, R. (2000). Why information technology inspired but cannot deliver knowledge management. In E. L. Lesser, M. A. Fontaine, \& J. A. Slusher (Eds.), Knowledge and communities. Woburn: Butterworth-Heinemann.

Orlikowski, W. (1992). The duality of technology: Rethinking the concept of technology in organizations. Organization Science, 3(3), 398 - 427.

Orlikowski, W. (2000). Using technology and constituting structures: A practical lens for studying technology in organizations. Organization Science, 11(4), 404 - 428.

Orlikowski, W., \& Robey, D. (1991). Information technology and structuring organisations. Information Systems Research, 2(1), 1 - 28.

Robey, D. (1979). User attitudes and management information system use. Academy of Management Journal, 22(3), 527 - 538.

Robey, D., \& Boudreau, M. (1999). Accounting for the contradictory organizational consequences of information technology: Theoretical directions and methodological implications. Information Systems Research, 10(2), 167 - 185.

Robey, D., \& Markus, L. (1984). Rituals in information system design. MIS Quarterly, 8(1), 5 - 15.

Scacchi, W. (1981). The process of innovation in computing: A study of the social dynamics of computing. Unpublished Ph.D. Dissertation, University of California, Irvine.

Schultze, U., \& Leidner, D. (2002). Studying knowledge management in information systems research: Discourses and theoretical assumptions. MIS Quarterly, 26(3), 213 - 242.

Silva, L. (2007). Epistemological and theoretical challenges for studying power and politics in information systems. Information Systems Journal, 17, 165 - 183.

Thomas, R. (1994). What machines can't do: Politics and technology in the industrial enterprise. Berkeley: University of California Press.

Walsham, G. (1993). Interpreting information systems in organisations. Chichester: John Wiley.

Walsham, G. (2001). Knowledge management: The benefits and limitations of computer systems. European Management Journal, 19(6), 599 - 608.

Walsham, G. (2006). Doing interpretive research. European Journal of Information Systems, 15, 320 - 330. 
Walsham, G., \& Hayes, N. (2001). Participation in groupware-mediated communities of practice: A sociopolitical analysis of knowledge sharing. Information and Organization, 11, 263 - 288.

Winfield, I. (1991). Organisations and information technology: Systems, power and job design. Carlton: Blackwell Scientific Publications

Zuboff, S. (1988). In the age of the smart machine. New York: Basic Book Publishers.

\section{Appendix A \\ IT Services Department Level 1 and Level 2 Organisational Structure - in 2006}

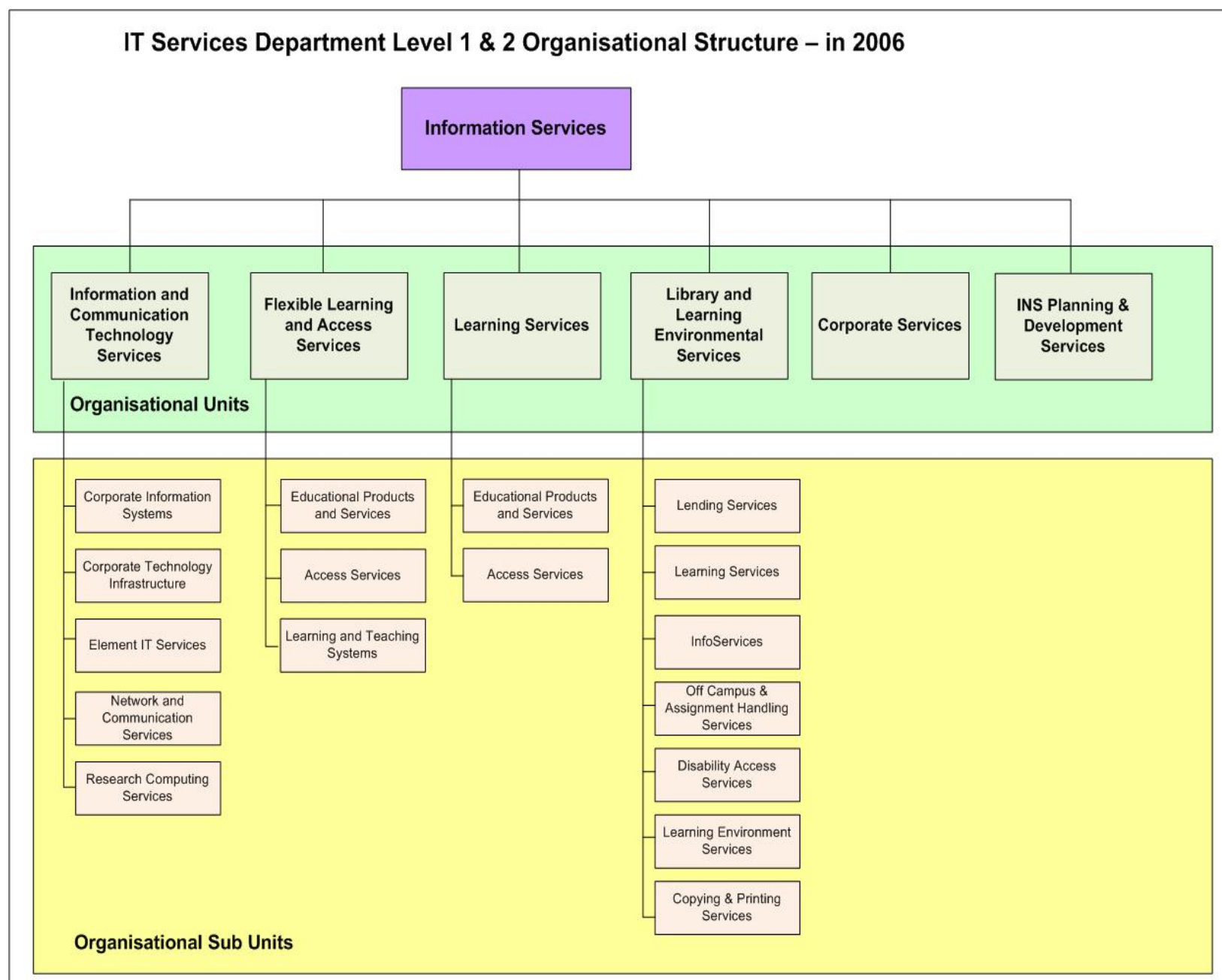




\section{Appendix B \\ IT Services Department Level 3 Organisational Structure - in 2006}

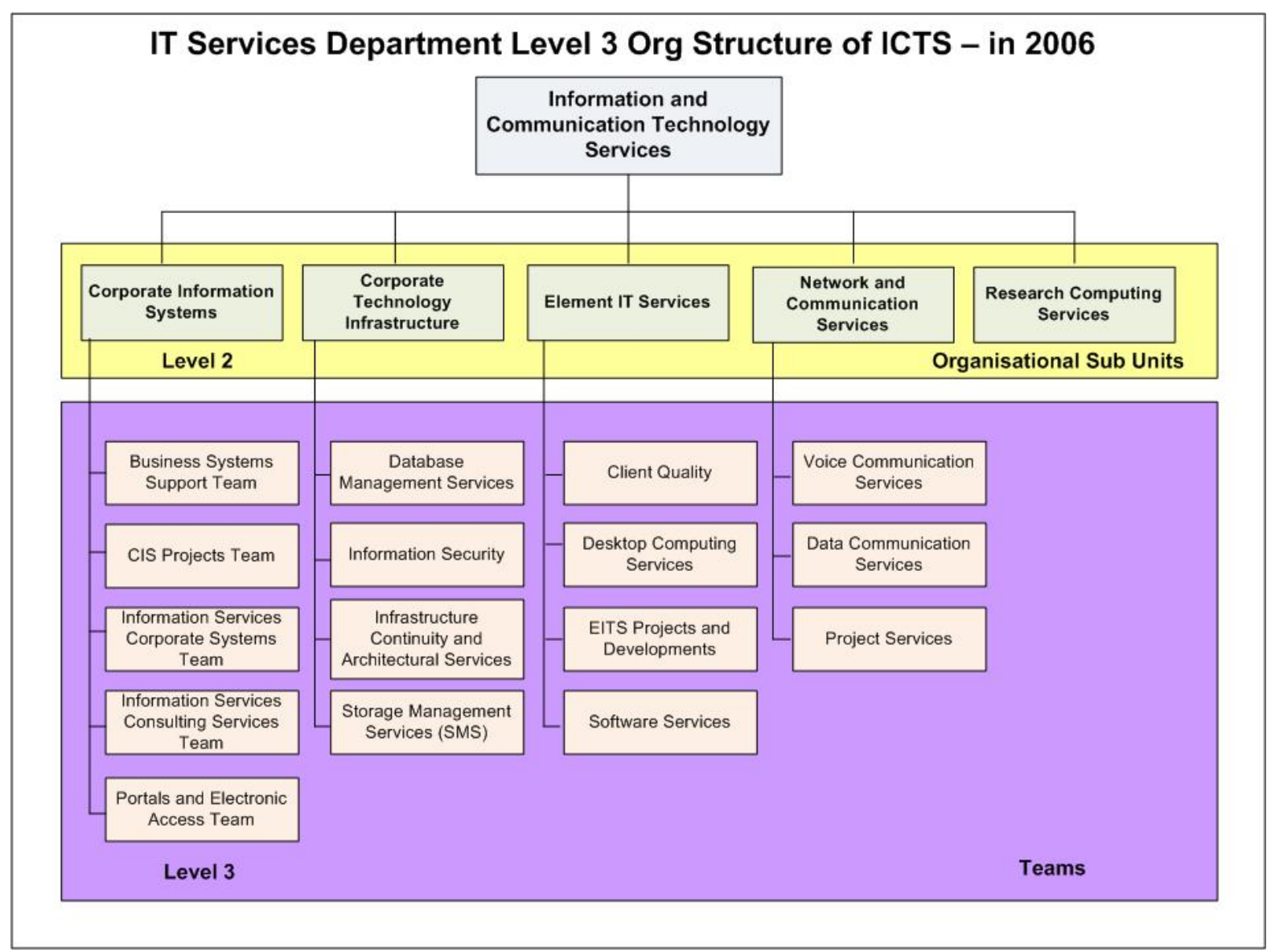




\section{Appendix C Data Collection Instrument - Interview Questions}

The following questions were used as guides to keep the conversation relevant to the topics of interest.

\section{Section 1 - Knowledge and Knowledge sharing}

1. Describe what you see as knowledge? So can IT capture and share knowledge?

2. Is there any barriers to it - what barriers does your work group experience? Emphasis on codification and interpretation

3. What is most essential to share knowledge?

4. How is the knowledge spread in the organisation? Equally spread or is there a key guy?

5. Is there any formal knowledge sharing policy in place? Else do you have your own?

Section 2 - Intra-Organisational Power

1. What do you see as 'power' in an organisational setting? Is this power in your organisational setting?

2. Do you think knowledge and power are related in any way? Please explain.

3. Any thoughts about IT and its relation to power?

\section{Section 3 - Knowledge sharing Tool}

1. Can you describe this lotus based lessons learned database with a bit of background?

a. Its purpose, target audience (where the idea came from)

b. Processes involved, example procedure

c. When and who implemented it, how long did it take? To a plan / adhoc? Changes?

d. For the same purpose?

e. Feasibility or usability study done, training conducted?

f. The procedure before the tool was implemented?

g. Any documentation relating to the tool?

h. Primary person moderator of the tool?

i. You perception / experience of the tool (from inception up to now)?

i. Availability of information to everyone on equal basis?

ii. Reason for contributing to and using its info?

iii. The measures taken to full fill the purpose of the system (Who is the go to guy / replacement for the tool)?

iv. Any protests and complaints? Senior manager's view?

v. Why has nothing been done so far?

vi. Is everyone aware of it? Were they informed? Why and why not?

vii. Any specific person who contributes to the tool?

\section{$\underline{\text { Section } 4 \text { - Demographic/ Behavioural Questions }}$}

1. What is your highest level of education?

2. For how long have you worked in your current role?

3. For how long have you worked at information services division of Griffith University?

4. How long have you been working in the university sector?

5. How many peers are working under / along with you?

6. Are you willing to accept other's knowledge at any given scenario?

7. Do you utilise someone else's knowledge that is readily accessible to solve a problem in your domain? Detail explanation.

Section 5 - Wrapping up

1. Do you think having this tool is worthwhile? Can I contact you for a follow up interview 


\section{Biographies}

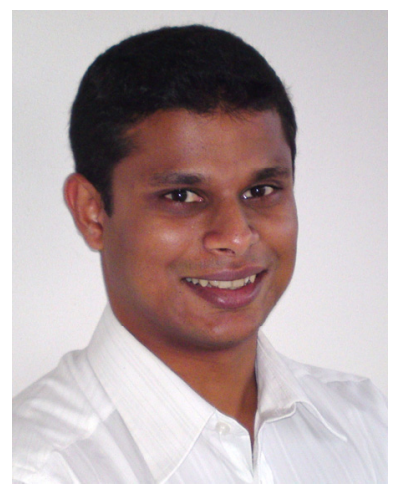

Lahiru Attygalle is a researcher and a teaching associate in the school of Information Communication Technology at Griffith University, Brisbane, Australia. He graduated from Griffith University with a $1^{\text {st }}$ class Honours and a specialisation in information systems. He was awarded the prestigious "university medal" in 2009 for demonstrating outstanding academic excellence at Griffith University. His research interest lies in the domains of information system adoption with a focus on organisational power, knowledge sharing systems, and interpretivism (as a school of thought).

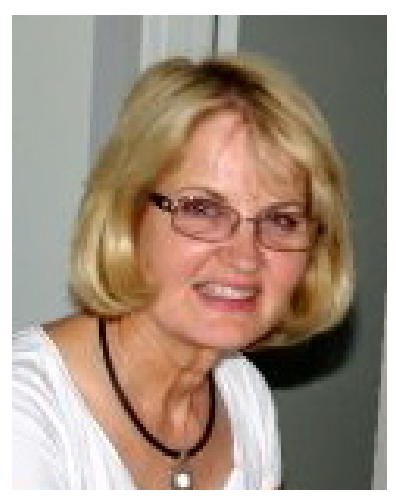

Liisa von Hellens is Fellow of Australian Computing Society and Associate Professor in Information Systems in the School of Information and Communication Technology at Griffith University. She is a published author on subjects of Enterprise Wide System Implementation, software quality management and women in information technology. Her PhD at Templeton College at Oxford University investigated package software development and use. Her current duties include serving as Associate Editor of the Information Systems Journal and cochairing the ICIS 2010 track for Human Capital and Information Systems. She served at the Editorial Advisory Board for the Encyclopedia of Gender and Information Technology (Idea Group Reference). She was invited by Senator Helen Coonan while the Federal Minister for Communications, IT and the Arts to sit on the Advisory Committee for the 2005 Summit on Women in ICT. In 1995, Liisa von Hellens and Sue Nielsen established the Women in Information Technology Project (www.winitproject.com). In 2007 Liisa was invited visiting Professor in Gender and IT in Hanover, Germany within the Maria Goeppert-Mayer programme.

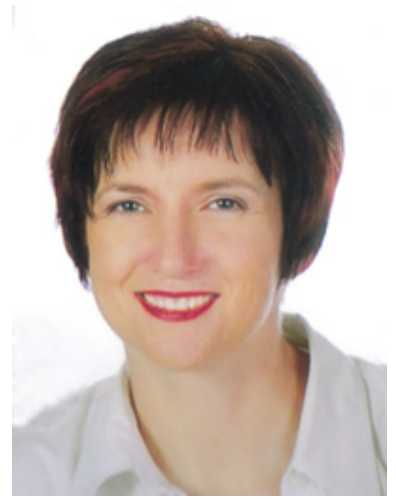

Leigh Ellen Potter is a lecturer in the School of Information and Communication Technology at Griffith University. She completed her $\mathrm{PhD}$ exploring the characteristics that differ between IT professionals and users, and her research interests include the relationship between IT professionals and the wider community, factors that draw individuals to an IT career, and the concept of a 'user generation'. Leigh Ellen's industry experience is in usability and business analysis, leading to a more general interest in Project Management and Agile technologies. She currently teaches in these areas as well as in organizational analysis. 